\title{
W-win Model Research on Construction of New Energy Vehicle Charging Facilities and Economic Development of the New Urban Yue $\mathrm{Yu}^{a^{*}}$,Lei Zhang ${ }^{b}$ \\ ${ }^{a}$ Nanjing University of Science and Technology, Nanjing, China \\ b Nanjing Xiaozhuang University, Nanjing, China \\ *Correspondence author: Yue Yu, Master, 175759394@qq.com
}

\begin{abstract}
Based on the analysis of the software and hardware characteristics of the new urban area (The new urban include economic development zone, University City, economic cooperation zone, science and Technology Park, etc.), we make full use of its advantages and design scheme of charging facilities construction and operation in the new urban area, open up a new road for the development of new energy vehicle charging facilities; meanwhile, the construction and operation of new energy vehicle charging facilities, the economic development of new urban area is promoted from social capital inflows, creating jobs, stimulating the real estate economy, creating a sustainable environment and reducing the cost of bus vehicles, saving financial expenses and so on. The development of new energy vehicles charging facilities and economy of new urban area are pushed into a virtuous circle of double wins.
\end{abstract}

Key words: new energy vehicle; the regional economy; charging facilities; w-win

\section{Introduction}

From 2014-2016 year, new energy automotive industry is frequently supported by policies. Pure electric type of new energy vehicles have been favoured by the government and the public, because of its advantages, such as energy saving, environmental protection and government subsidies, the use of low cost. It is predicted that the domestic new energy vehicles will be rapidly developed in the "13th Five-Year" period. However, currently, the development lag of new energy vehicle charging facilities has seriously hindered the further development of new energy automotive industry, and greatly affect the effective implementation of China's long-term strategic policy related to energy conservation. How to solve this problem has become a top priority in the development of new energy automotive industry.

\section{Development status of charging facilities for new energy vehicles}

At present, charging facilities industry has been the concern of the government and society. Since September 2015, policies related to charging pile is issued intensively. A total of seven major policy documents are issued. Under the action of the new energy automobile circulation surge and government policy support, charging facilities industry will go into a fast growing period.

However, charging facilities development is encountered many obstacles, because of the city's urban infrastructure and economic environmental impact. As follows: 


\subsection{Scarcity of land resources to curb the development of charging Enterprises}

In recent years, the high price of land is a common phenomenon. Land resources are not only high prices, but also the use of planning strictly control. Not only charging piles and charging stations need to occupy the land, the substation facilities need to occupy land, land acquisition difficulties of the charging facilities construction has become the consensus within the industry.

\subsection{Poor compatibility and low utilization rate of public charging facilities}

According to the Maps APP, Charging piles can be seen everywhere, but the car users found that most of the charging pile can be unused. In fact, Charging is a big problem. The biggest reason is that charging interface standard of the public charging pile is not unified. At the same time, many public charging pile parking spaces are occupied by ordinary fuel vehicles and damage rate of facilities is high for lack of management and improper use, thus affecting the efficiency of the use of charging facilities.

\subsection{Big difficult and high risk of Home charging pile}

Home charging piles need to have fixed parking spaces, and needs to be match with the residential property committees. In reality, the residential property committees have no profit and may take some security risks, especially in the some old district, face with the problem of circuit transformation and serious shortage of parking spaces. Therefore, although the country has repeatedly guide and support the charging infrastructure, but home charging piles is always the problem.

\subsection{Single and poor convenient mode of payment}

Public charging pile and centralized charging stations are needed to pay fees according to the time, the quantity and the times. At present, payment methods include cash or bank card, which are relatively simple, and poor convenient.

\subsection{High investment and low income of charging enterprise}

All charging facilities in the early stage of construction need to be invested huge amounts of capital. Firstly, due to the long charging time, large volume of cars, companies need to purchase or lease a larger area of the site. Secondly, companies spend a huge amount of money to buy and install charging facilities, and improve the circuit according to the use of electricity. Then, after the completion of the charging equipment in the operation process, companies spend and bear the electricity fee and labour costs, a late maintenance and repair costs. According to statistics, in accordance with the current operating conditions, it is 5 years after the initial investment to achieve balance between income and expenditure.

\section{Reasons for new energy vehicle charging facilities are selected to develop in the new urban areas}

The development of new energy vehicles are greatly hindered by the above obstacles, and the effective implementation of long-term strategic policy environmental protection are restricted by these obstacles. The way to solve the above problems is to take the lead in the construction and operation of charging facilities in the new urban areas. The new urban areas include 
economic development zone, University City, economic cooperation zone, science and Technology Park, etc. We can not only promote using breadth and latitude of new energy vehicles in a certain extent, achieve the purpose of energy saving and environmental protection, but also attract all kinds of social capital (including business investment and private living consumption) into the regional economy, and promote the fast development of the economy in this region. Because these areas have a unique priority hardware and software conditions, we choose to take the lead in the construction and operation of charging facilities in the new urban areas, and vigorously promote the use of new energy vehicles.

\section{Design of charging facilities construction and operation in the new urban areas 4.1 Multi-way to solve the problem of land resources}

In recent years, the urban planning of the old urban areas has been not set aside this kind of land, and land price is soaring. These reasons lead to the inability of enterprises to bear the enormous burden. Compared to the old urban areas, land resources are abundant in new urban areas, and some regional land planning work is not over yet. The government can set aside the land for these projects in the planning or change the plan. In addition, land prices are cheaper in these areas, and within the scope of the charging enterprise can bear. It is feasible that the implementation of the existing gas stations to add charging facilities or the excess gas stations to be converted into a centralized charging station. The goal is to speed up the construction of charging facilities, reduce the capital cost of the most pre construction. In addition, the original car park is divided into a part of the region, as a new energy car parking lot. Charging piles or centralized charging stations are built according to the passenger flow and parking scale. Such measures can save the cost of land.

\subsection{Uniform charging facilities standards and improve its usage}

The unity of charging facilities is the precondition of ensuring its high usage rate. However, the interface types and structures, voltage or mechanical lock sizes and APP of the charging facilities are different in different charging enterprises. So we can take some measures: (1)the interface of each enterprise's charging facilities must be unified. (2)each enterprise APP can be mutually compatible, cooperating with Baidu map, High German navigation and other traffic Internet business. Users can download only one APP to be able to learn about the vacancy situation of the charging facilities from the various enterprises in the vicinity, find and order in advance the nearest vacant charging facilities with the fastest speed. These measures lead to convenience of customers, improving the overall utilization of charging facilities, expanding the industry's profitability.

\subsection{To speed up the domestic charging pile construction through the various aspects of cooperation}

Installing home charging facilities result in more work burden and difficulty that residential property committee born. Residential property committee was given compensation through government subsidies or increasing user charging fees and other ways. It is the basic premise that the voltage is transformed or redistributed by the power supply department. Circuit transformation requires the district property committee, the government and the relevant 
power sector to work together. Based on part of the circuit and parking spaces in the new areas have been met requirements of home charging pile consumption or only need to make a little transformation, it is feasible that home charging piles are configured according to the needs of the owners and parking spaces. Users of new energy vehicles can use idle time to charge, which Great is convenient for user, and reduce the cost of using a car.

\subsection{Diverse, convenient and quick the payment method}

Payment Method of public charging piles and centralized charging stations will be multiple. Single payment method (only including cash and bank card) is not conducive to the development of charging facilities. The enterprise actively cooperates with various third party payment systems (such as: Wing payment, Alipay, WeChat payment and other). Users can pay via mobile phone or computer directly without cashier, which greatly improve the use of roadside public charging pile, and reduce the labor cost, and improve enterprise profit.

\subsection{Adding models and use of new energy vehicle}

\subsubsection{Public Vehicles}

In the rule of the new urban infrastructure construction, government set aside a large area for public transport, such as: bus parking, which provides convenience for the selection of new energy buses. Because a large area of the bus parking lot can be installed dedicated highpower charging facilities, be uniformed configuration of voltage and capacitance lines in line with higher requirements. These facilities provide the electric power protection for new energy bus. A variety of public health vehicles (including road cleaning vehicle, watering cart and garbage transport vehicle) and all kinds of patrol cars can be updated by new energy vehicles. Because of these vehicles have some fixed parking spots. Installation cost of charging facilities in the parking lot is very low. There is no land fee, no construction cost, and no special artificial management fees. If the newly purchased public vehicles are all new energy vehicles, we can reduce long-term car costs (because the electricity price is cheaper than the oil price, When we buy a car and enjoy the state subsidies), and optimized environment. It is beneficial to our future generation.

\subsubsection{Logistics Vehicles}

In view of these characteristics, such as cheap land prices and convenient traffic conditions, most of the emerging logistics companies focus on these areas. They invest in these areas to buy land at a low price, build a plant, and build large logistics truck parking lot and distribution logistics product storehouse. It is high efficiency, low cost, convenient and quick to configure charging facilities in these parking lots and storehouses. Once the government gives preferential taxation and subsidies and other administrative policies to encourage logistics enterprises to use the new energy logistics vehicles (including medium and large logistics freight car and small express delivery vehicle), the changeable cost of logistics enterprise is greatly reduced, and corporate profits have been raised.

\subsubsection{Factory Bus and School Bus}

There are a number of special vehicles in the new city. They are factory bus for workers and school bus for teachers and students. These special vehicles are frequent use and great fuel consumption, which is huge expense for business and learning. Factory and school choose 
new energy vehicles in the update, and greatly reduce the cost. Furthermore, factories and schools had fixed the location for bus; it is easy to configure charging facilities

\subsection{New energy vehicle leasing reform car-rental business}

The middle aged and young people are not only familiar with the use of mobile phones APP and online payment system, but also have the passion and the desire to receive new things. They don't have the capital to buy a car, but they have a dream to drive. If the government support time sharing lease and finance lease of new energy vehicles in these areas, coupled with good road conditions and full network coverage, new energy vehicle time sharing lease will reform car-rental business.

\section{New energy vehicle charging facilities to promote regional economic development in the new urban area}

The above measures are based on the characteristics of the new urban area. Government takes the lead in construction and operation of charging facilities to expand the popularity of new energy vehicles in the new urban area. There is a multi-angle, multi-level, multi- direction meaning to develop the regional economy.

\subsection{To attract social and corporate capital inflows}

Convenient transportation, low transportation costs, attractive land prices, preferential tax policies attract a large number of enterprises in the old urban areas to move to the new areas, and attract new enterprises to buy land, build a factory and settle down, Change the management mode of enterprises and the life style of enterprise employees (including: using new energy transportation, buying housing in the new urban areas and consumption), attract a large number of enterprises and talent to the new urban areas. Business and talent bring capital inflows, at the same time, they make money and consume here, which stimulates the economic operation of the region, stimulating the region's economic consumption.

\subsection{Providing employment opportunities}

All charging piles are required for professional management or operating personnel, which provide a large number of emerging professional jobs for the community. The production and operation of charging facilities and the rise of the industry provide a large amount of related management, production, finance, technology research, sales, and maintenance work. Some Job opportunities with lower technical requirements are filled by the local residents who lose the land, Some Job opportunities with higher technical requirements are filled by high-tech talent from other areas. The basic demand of life is stimulated, and the economic development of the region has been promoted.

\subsection{Stimulating real estate economy}

After the favourable opportunities and policies to attract enterprises and talents, the entire real estate market (including commercial housing and shops) has been activated. Enterprise building and construction needs land, commercial housing and retail development needs land, government public construction needs land. Land and buildings on the ground will be a pillar 
industry in the region's economy, be a major source of government revenue, be effective power of stimulating the economic growth.

\subsection{Creating a sustainable environment for development}

Government vigorously develop and invest in the region to build related charging facilities, give more preferential tax and electricity subsidies to enterprises in the procurement, severely punish enterprises that destroy the environment. All the enterprises are keenly aware of the long-term policy of energy saving and environmental protection. Companies understand that they want to go on a sustainable development path for a long time.

\subsection{Reduce the long-term cost of vehicles, saving financial expenses}

Characteristics of governments and subordinate administrative institutions in the use of cars are wide range, high frequency, large cost. According to these characteristics, future bus purchases tend to be new energy vehicles. Government will reduce long-term car costs, and save financial expenses. Compared to the private new energy vehicles in the rental market, it is highlight to try to lease new energy vehicles for government agencies, public institutions, colleges and universities, companies. Through the new energy vehicle self-service sub lease, aim at saving government spending and effective allocation of resources. It is so-called:” killing two birds with one stone".

From the following Fig. 1, we can clearly see that: the development of new energy vehicle charging facilities and the development of new urban areas economy run into a win-win positive circular orbit.

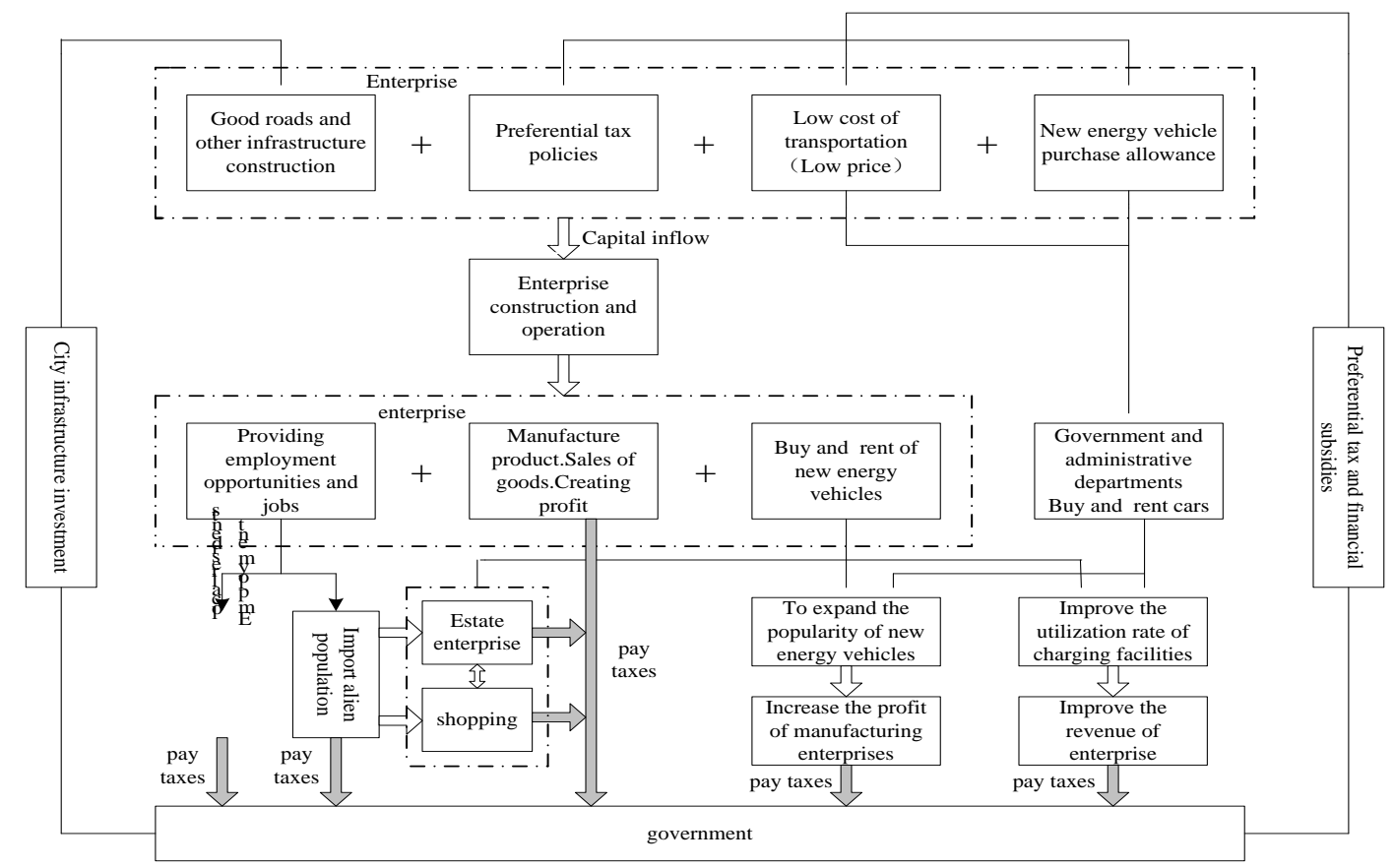

Fig. 1 - Win-win circulation chart about the development of new energy vehicle charging facilities and new urban areas economy

\section{Conclusion}

In the era of rapid development of new energy vehicles, the development lag of new energy vehicle charging facilities seriously hinder the further development of new energy automotive industry. Based on the analysis of the software and hardware characteristics of the new urban 
area, we make full use of its advantages and design scheme of charging facilities construction and operation in the new urban area, open up a new road for the development of new energy vehicle charging facilities; meanwhile, Through the construction and operation of new energy vehicle charging facilities, the economic development of new urban area is promoted. The development of new energy vehicles charging facilities and economy of new urban area are pushed into a virtuous circle of double wins.

\section{Acknowledgements}

The Natural Science Foundation of Jiangsu Province (BK20151574).

\section{References}

1. Y. Q. Liu, M. Wang, J.Y. Wang, Forecast of China's new energy vehicle market, J. Economics and Management Studies. 4(2016)86-89.

2. H.S. Wang, Y.M. Zhang, Cloud Innovation: new energy automotive industry development model -- BYD new energy vehicles as an example, J. Research on science and technology management. 23(2015)195-199

3. T.Y. Zhong, R. Du, Research on the subsidy strategy of new energy vehicles based on Game Theory, J. Management Science in China. 11 (2015)818-821. 